\title{
Fothergill and Carnett signs and rectus sheath hematoma
}

\author{
Steven H. Yale ${ }^{1}$, Halil Tekiner ${ }^{2}$, and Eileen S. Yale ${ }^{3}$ \\ ${ }^{I}$ Department of Internal Medicine, University of Central Florida College of Medicine, USA \\ ${ }^{2}$ Department of the History of Medicine and Ethics, Erciyes University School of Medicine, Turkey \\ ${ }^{3}$ Division of General Internal Medicine, University of Florida, USA
}

\begin{abstract}
Fothergill and Carnett signs are used to distinguish intrabdominal from abdominal wall diseases. These bedside techniques may be useful in distinguishing intrabdominal from an abdominal wall cause of disease. Timely and accurate diagnosis of rectus sheath hematoma in at risk patients in the appropriate clinical setting is important because of the associated morbidity and mortality associated with this condition. Diagnosis requires an accurate and thorough history and bedside physical examination and performance of these maneuvers as originally described.
\end{abstract}

Key words: eponym, Fothergill, Carnett, sign, abdominal wall

\section{To the Editor}

We read with interest the manuscript "Spontaneous rectus sheath hematoma associated with warfarin administration: a case report" by Takahashi et all). There are two bedside maneuvers or signs, one of which was reported by the authors, that should be considered particularly at rural health care sites where advanced medical technology may be limited. As in the case described, rectus sheath hematoma most commonly occurs unilaterally and in anticoagulated patients ${ }^{1)}$. Hemorrhage occurring below the arcuate line of Douglas, may cause blood to extravasate laterally deep to the aponeurosis of the oblique muscle, while bleeding above this line remains confined to but may displace the rectus sheath to the contralateral side ${ }^{2)}$. Although it may occur spontaneously, other risk factors include conditions which causes contraction of the rectus abdominus muscles

Received: December 9, 2019

Accepted: March 8, 2020

Correspondence: Steven H. Yale, Department of Internal Medicine, University of Central Florida College of Medicine, 6850 Lake Nona Blvd., Orlando, FL 32827, USA

E-mail: steven.yale.md@gmail.com

This is an open-access article distributed under the terms of the Creative Commons Attribution Non-Commercial No Derivatives (by-nc-nd) License $<\mathrm{http}: / /$ creativecommons.org/ licenses/by-nc-nd/4.0/>. such as coughing, twisting, abrupt changes of position, and vomiting as reported in this case $\mathrm{c}^{1,2)}$.

In patients presenting with abdominal pain it can be difficult to determine whether the source of pain is emanating from either the abdominal wall or an intrabdominal process. There are two physical examination signs of the abdomen described by Fothergill and Carnett, which may facilitate rapid and accurate bedside diagnosis ${ }^{2,3)}$. William Edward Fothergill (1865-1926) described in the British Medical Journal in June 1926 a method for detecting an abdominal wall hematoma:

The most interesting thing about these cases is the diagnosis. The patient complains of pain and the medical man finds the swelling. The trouble is that he seldom knows how long the swelling has been present; for patients frequently have masses of various kinds in the pelvis or abdomen who presence is not suspected until they complain of pain and submit to examination. The main point is the recognition that these swellings are part and parcel of the abdominal wall. This is generally made by noting that they can still be felt when the recti are in action, and that they become fixed as the muscles contract. Another point is that, when a mass in the abdominal wall is not too large, a resonant note may be obtained through it by deep percussion (p. 942)

Thus, Fothergill sign refers to the presence of palpable rectus sheath mass that remains fixed in position, felt when 
the muscle is contracted or relaxed, and resonant on percussion. John Berton Carnett (1890-1988) in his paper "Intercostal neuralgia as a cause of abdominal pain and tenderness" also published in May 1926, described a two stage (A and $\mathrm{B}$ ) palpable bedside maneuver for differentiating whether the source of abdominal pain is emanating from either the abdominal wall or intrabdominal lesion:

(A) In any patient complaining of abdominal pain and tenderness, the examiner follows the classic advice of gaining the confidence of both the patient and his muscle and then palpates in the usual manner. Irrespective of whether the tenderness is parietal or intrabdominal the examiner's fingers as a rule, will dip fairly deep into the abdomen before tenderness is elicited. The deep position of the fingers has generally been regarded as proof that the tenderness is intrabdominal, but in a surprisingly high percentage of cases this assumption will prove to be an error as shown by the next step. (B) The examiner keep his fingers at the most sensitive area he has discovered on deep pressure and requests the patient to make his abdominal muscles rigid by contracting his diaphragm or by raising and holding his head from the pillow; as the patient tenses his muscles, the examiner relaxes his finger pressure so that his fingers rise out of the $a b-$ domen; and then with the patient's abdominal muscle tense the examiner reapplies pressure with his finger tips and he also may exert a little twisting motion with them (p. 625) ${ }^{4)}$.

If the source of abdominal pain is caused by intrabdominal pathology than only the A test will be positive. However, if the abdominal wall is involved than both the A and B test will be positive ${ }^{4,5)}$. Thus, a positive Carnett sign is when both parts $\mathrm{A}$ and $\mathrm{B}$ of the test is positive.

Based on the timeline when the signs were reported it is unlikely that either Fothergill or Carnett were aware of each other's findings. Both recognized the limitations associated with these maneuvers. Fothergill stated that a positive test may be found in patients when the abdominal mass become adherent to the abdominal wall, while Carnett recognized that the part B may be positive in cases of peritonitis or local abscesses involving the anterior parietal peritoneum or muscle or in multiparous women who are unable to tense their abdominal muscles ${ }^{3,4)}$. Studies have shown that Carnett sign may be useful bedside diagnostic test for determining abdominal wall involvement ${ }^{6-8)}$. Diagnosis requires an accurate and thorough history and bedside physical examination and performance of these maneuvers as originally described.

\section{References}

1. Takahashi K, Nihei T, Aoki Y, et al. Spontaneous rectus sheath hematoma associated with warfarin administration: a case report. J Rural Med 2019; 14: 245-248. [Medline] [CrossRef]

2. Holmes SJ, Yale SH, Mazza JJ. Rectus sheath hematoma as a cause of acute abdominal pain. Am Fam Physician 2001; 64: 1681-1682. [Medline]

3. Fothergill WE. Haematoma in the abdominal wall simulating pelvic new growth. BMJ 1926; 1: 941-942. [Medline] [CrossRef]

4. Carnett JB. Intercostal neuralgia as a cause of abdominal pain and tenderness. Surg Gynecol Obstet 1926; 42: 625-632.

5. Carnett JB. Pain and tenderness of the abdominal wall. JAMA 1934; 102: 345-348. [CrossRef]

6. Thomson H, Francis DMA. Abdominal-wall tenderness: a useful sign in the acute abdomen. Lancet 1977; 2: 1053-1054. [Medline] [CrossRef]

7. Greenbaum DS. Chronic abdominal wall pain (CAWP). Neurogastroenterol Motil 2007; 19: 75. [Medline] [CrossRef]

8. Thomson WHF, Dawes RFH, Carter SSTC. Abdominal wall tenderness: a useful sign in chronic abdominal pain. Br J Surg 1991; 78: 223-225. [Medline] [CrossRef] 